\title{
The Desolation of Nihility: Aesthetic Analysis of Japanese Domestic Ceramics from the Perspective of Japanese Zen Culture
}

\author{
Anfei Jiang $^{1 *}$, Jinbo Sun ${ }^{1}$ \\ ${ }^{1}$ University of Sanya, Sanya, Hainan, 572000, Chinaountry
}

\begin{abstract}
The culture of Zen comes into two diverse paths in China and Japan. Compared to China, the Japanese Zen culture has characteristics of natural, plain, sensitive, vanity and silence. It is unrestrained with feeble and desolation. And these characteristics are presented in Japanese domestic ceramic in the unique beauty of its domestic ceramic.
\end{abstract}

\section{Introduction}

The so-called Zen culture has two levels of meanings: the first level includes the general term for the thoughts, living habits, and lifestyles formed by the school of Zen, such as the jungle system. The second level refers to the general name of various literature, art, and customs under the influence of Zen thoughts, such as Zen poems, Zen paintings, and Zen tea.

\section{Zen culture in Japan}

On the surface, Japanese Zen and Chinese Zen seem to be just as happy to be natural, peaceful, casual and empty, but there is a fundamental difference: Japanese Zen does not keep precepts. The factors leading to this characteristic are mainly derived from the Japanese "object sorrow" aesthetic culture and bushido culture.

Sorrow is a special term of Japanese aesthetic culture, that is, sorrow for things. Subconscious in Japanese don't believe in eternity. They feel the world with a melancholy and sensitive heart. Aesthetic psychology of sorrow in Japanese people makes them accept the vagaries of Zen quickly. In Japanese culture, precepts can be ignored because they don't believe in eternity. They are not willing to, or impossible to, focus more on mining deep steady foundation of Zen Culture.

In addition, the practice of Zen Culture has many kinds of resonates with Bushido. But the Zen meditation of the Samurais has the characteristics of secular, realistic, spiritual freedom and achieve the ultimate goals of life directly in Zen culture. Because the samurai class could not abstain from killing and drinking alcohol, the Zen Culture gradually lost the requirement of maintaining the precepts when it came to Japan.

To sum up, seen from the outside, Japanese Zen culture and Chinese Zen culture advocate simplicity, leisure and quiet. Seen from the inside, there are fundamental differences between the two countries. The Zen culture in Japan has evolved into a rule system without monastic rules and precepts for Buddhists. In artworks of Japanese Zen culture, true nature and profound emotions with nihility can be identified, while slightly feeling of decadent sorrow, nihility, and desolate beauty characteristics.

\section{The beauty of Zen culture in Japanese domestic ceramic design}

Domestic ceramics refer to ceramic products that are used in daily life, such as cups, dishes, dishes, bowls, etc. Come up from manufacturing methods, domestic ceramics can be divided into two kinds: handmade and mechanized production.

Because of the lack of discipline in Japanese Zen culture, Japanese Zen is more secular than Chinese Zen. Zen culture in Japan is more integrated into practical art. In the field of domestic ceramic design in Japan, influences from Japanese Zen culture can easily be identified.

\subsection{The beauty of freedom and natural}

The so-called "spontaneous nature" means the material, shape, and decoration of crafts can embody the Zen culture vision of " one flower opens five leaves and the fruit grows naturally". Their aesthetic achievements are unintentional and natural. The so-called "pamāda" means, in the process of creation, improvisation and entertainment are strong and informal, and the process reflects the secular side of human nature. This kind of work appears to have lasting appeal, sometimes appears to be crude insipid.

As shown in Figure 1, the materials of these plates are rough and natural clay, which is randomly formed by 
blank forming or clay board forming in the production process. In the drying process, artists used no extra blank repairing for the body and tried to maintain its natural molding state. The decoration of these vessels are simple, rust flowers, just like a natural glaze. The composition of their decoration is concise and aplomb, produced by a calligraphy pen, color glaze painters. The color glaze is used as gender spray or paint, with no bone the spring, just like dance or flower. Artists' painting skills and layout arrangements show the vitality and vigorous nature with unique individual character. From their works, the charm of natural creation can be found with the feeling of the artist's romantic, dramatic character.

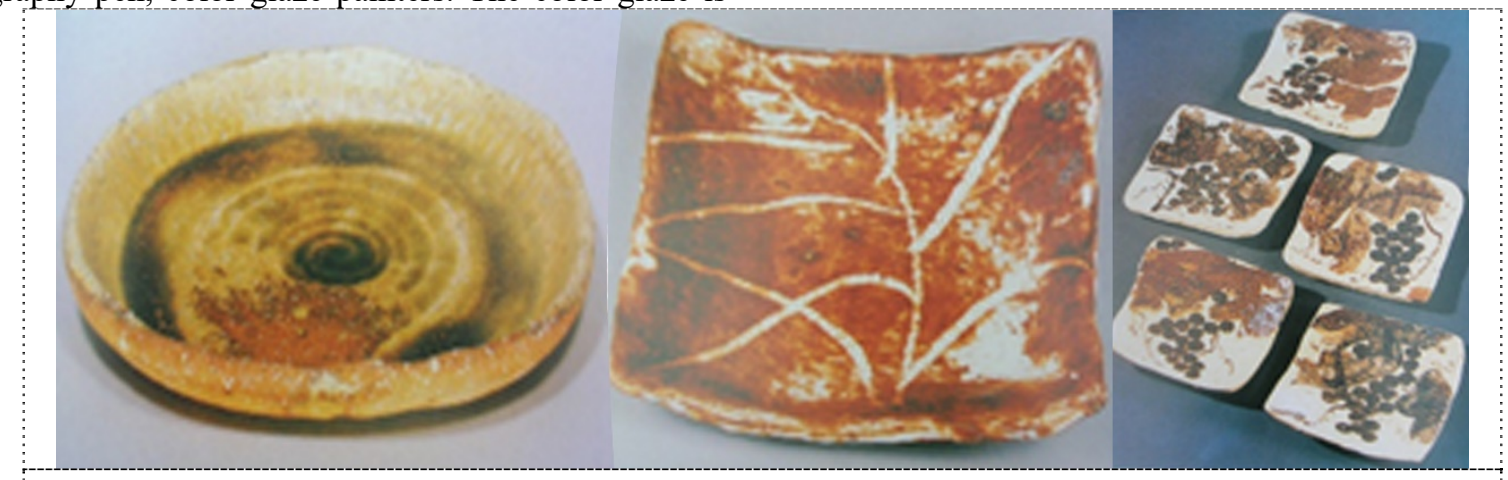

Figure 1. Color Glaze Plates.

\subsection{The beauty of simplicity and simplicity}

The so-called " essence of plain and simple " means, the decoration and modeling of pottery and porcelain works are not luxuriant and delicate, while with the feeling of guilelessness and freedom out of the living world. From the perspective of Zen culture, these art creations are accord with the perspective of "no mind, no appearance, no residence", to achieve a Zen-style of "purification" and natural effect. With the perspective of "no writing", it sweeps away the vanity of the artificial world and restores the authenticity of the nature of heaven and earth.
The special aesthetic psychology of the "sorrow" of the Japanese nation, is always a kind of dull and indifferent sorrow for things and objects. Therefore, Japanese ceramic works reflect the aesthetic culture of both simplicity and dryness.

As shown in Figure 2 and Figure 3, Shino Tea Bowl's style presents a "the most delicate Zhuo" meaning, no matter from the shape or decoration. The "coarse" in their modeling, decoration and is concise and indifferent. The smell the breath of deadwood in the field and the faint earth fragrance in the mountain village can be identified...

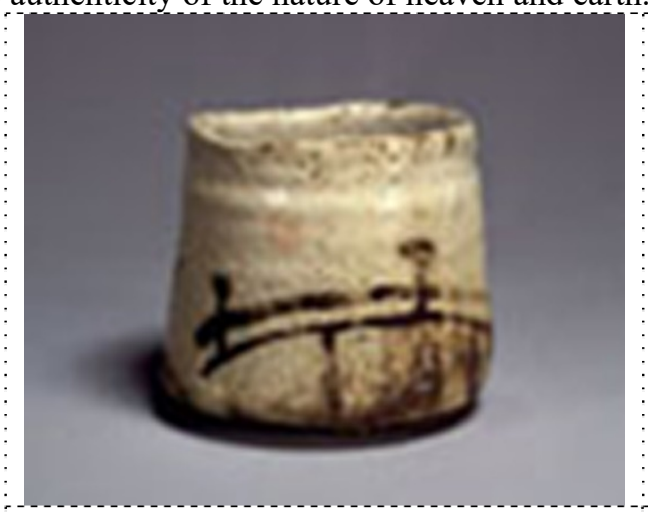

Figure 2. Shino Tea Bowl (Sample 1)

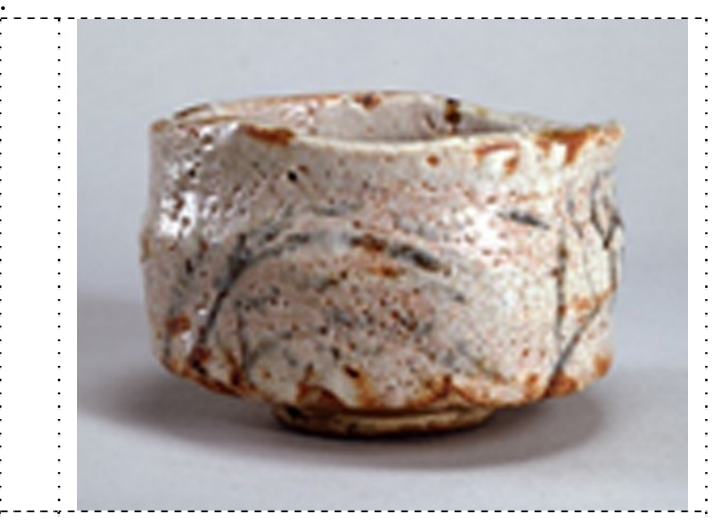

Figure 3. Shino Tea Bowl (Sample 2).

The artist applied a pure thick feldspar glaze to its slightly rough soil, which was burnt as white as snow, with flakes and speckled honeycombs. The bottom foot and the contracted glaze reveal the red color of the kiln. A few simple and clean strokes on the body painting leave enough space and consciousness of painting, with the simple idea of Zen. Tacitus tea charm is expressed through simple shape and decoration to convey a dry and indifferent.

\subsection{The beauty of pure, sentimental and delicate}

The so-called "innocent love " in Zen culture means, through the observation of "self", the soul is washed into the pure true nature. The so-called "pure heart" in Zen culture is filled with sincere pity for everything in the world. In Chinese Zen, due to the commandments, the feeling of pity is accord with "no image outside, no heart inside". The Japanese nation of sensitivity has a cherry 
blossom slender weak character. The sentimental characteristic comes naturally in their ceramic works.

As shown in Figure 4, the combination of tableware is different from the general mechanism of domestic ceramics. The style of this set of tableware is not a single repetition of the rigid shape. With a variety of combinations of curves of different ranges and lengths, the style of the tableware has been formed a rich visual effect. Because of the softness of the curve, this set of

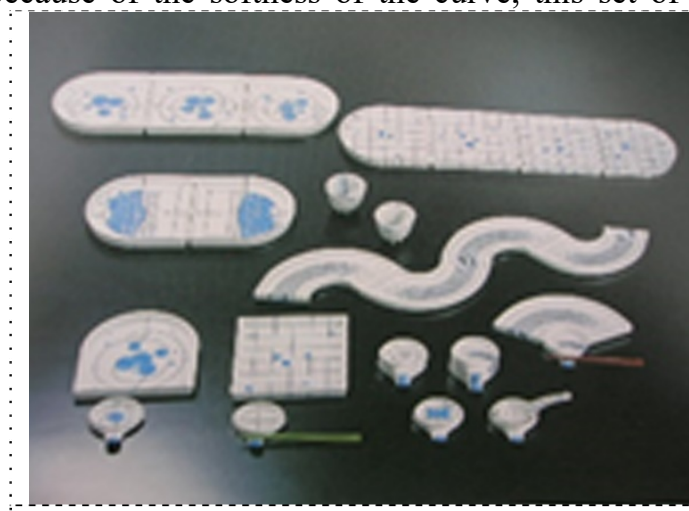

Figure 4. Tableware set

As shown in Figure 4, the modeling of the tableware set goes up many curves and downy ribbon, and their asymmetrical combination shows the psychology of the thin line and dots on decoration. They are reflected in Japanese sensitive and delicate aesthetics. The modeling of Figure 5 of the jars is the inverted triangle form of the big bottom, and their tapering bottom feet resemble a touch of a combination of hazy and downy adornment effect, filling worn delicate and weak temperament.

\subsection{The beauty of emptiness and desolation}

The nihility in Zen culture is based on the impermanence of the world. The Loneliness in Zen culture is based on the destination of annihilation. The Idle in Zen culture is based on liability. The gentle in Zen culture is based on liberation. In the Vajracchedika-sutra, the election of "all can be accomplished, such as dream, dew, lightning, should do as buddha." It refers to the theory of impermanence. In Zen Buddhism, through the observation of impermanence, one enters the realm of "all things are nihility, all troubles are silent". This understanding of Zen and the traditional Japanese mechanism product is full of gentle human touch. The color collaboration is white and sky blue to create a kind of pure and pure atmosphere.

As shown in Figure 5, the fragrant fume jar also has been decorated with the color combination of pure blue and cyan. The waist shape of the jar shrinks slightly inside in a soft and round way. The inverted triangle bottom foot is delicate and cabinet, just like a young slim graceful girl.

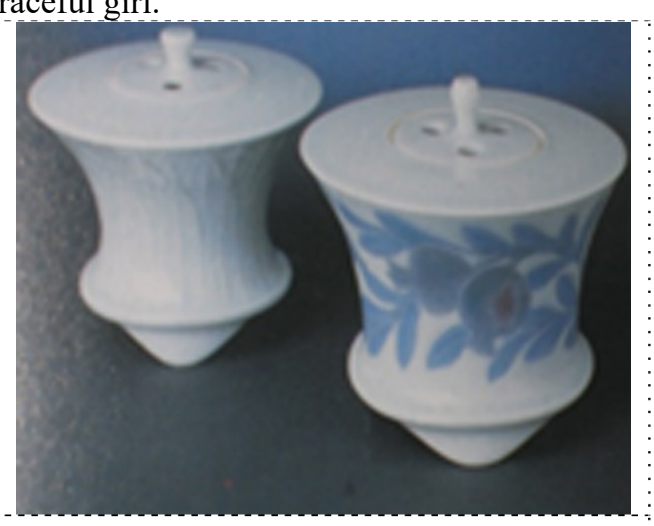

Figure 5. Fragrant fume jar.

aesthetic "Sorrow" combined to form a "pursuit of incomplete and consciousness beauty. In fact, this phenomenon reflects the Japanese nation's core aesthetics of potential frustrated, powerless, nihilistic heart, things and things of the pessimistic mood.

As shown in Figure 6, the ordinary ceramic vessel has broken gaps and cracks on its mouth and body. Their simple, monotonous shape and color almost make people feel that this is a broken and randomly placed defective work. However, the Zen culture of Japanese ceramic art is embodied in pursuit of the imperfection and incomplete to the object beauty. Infinity can be seen in nihility and eternity and can be experienced in silence. Its drab modeling, color, and luster can make a person experience a kind of leisurely and complacent, without false decorate and life restrain. The beauty emphasizes a kind of implicitness inside collect. The broken places make people feel the impermanence and fragility of life. At the same time, a feeling of self-reflection and treasure has raised in the appreciation of beauty. It makes people's pain to get relief from sadness, finally into a leisurely and a state of indifferent beauty.

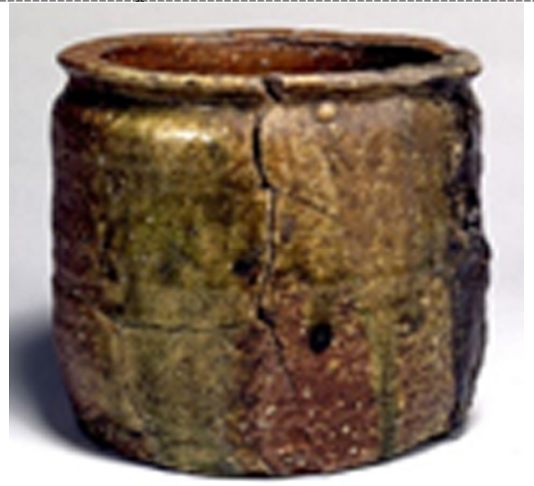

Figure 6. Color Glaze Plates. 


\section{Conclusion}

Japan's domestic ceramic design fully embodies the nation connotation of the cultural and spiritual, presenting its unique beauty. With the awareness of fully understanding and exploring their own cultural characteristics, great works are worthy of research and learn. To create great design works, the designer needs to Emphasize national characteristics, absorb the excellent results of other countries, avoid blindly copy. Only in this way can we have a breakthrough design concept and excellent design works.

\section{Acknowledgments}

This work was supported by Higher Education Educational Reform Research Funding Project of Hainan Provincial (Project No. Hnjg2018-68) and University of Sanya Fist Class Undergraduate Courses construction Project (Project No. syxyylbkkc02-06).

\section{References}

1. N Zheng. (2001) Japanese Pottery. Heirongjiang Art Publishing House, Haerbin.

2. W. Ye. (2003) History of Japanese Culture. Guangxi Normal University Press, Nanning.

3. M. Yanagi. (2006) Craft Cultuer. GuangXi Normal University Press, Guilin:

4. S. Wang. (2006) Modern Design History of World. China Youth Press, Peking.

5. A. Li. (2003) Ceramic Design. China Academy of Art Press, Hangzhou.

6. J. Shen. (2017) Research on Domestic Ceramic Design Based on Youth Consumers' Aesthetic Needs. China Ceramics, 53(09):88-92. 